УДК 338.242.4

08.00.00 Экономические науки

\section{АГРОПРОМЫШЛЕННЫЙ КОМПЛЕКС И ЕГО РОЛЬ В ОБЕСПЕЧЕНИИ НАЦИОНАЛЬНОЙ ПРОДОВОЛЬСТВЕННОЙ БЕЗОПАСНОСТИ}

Мельников Борис Александрович

соискатель экономического факультета

melnikov_ba@gw.tander.ru

Кубанский государственный аграрный

университет им. И.Т. Трубилина, Краснодар,

Россия

Дана комплексная оценка состояния агропромышленного комплекса России и определена его роль в обеспечении национальной продовольственной безопасности. Обоснованы основные направления обеспечения государственного продовольственного суверенитета в условиях глобальных вызовов. Представлена схема взаимодействия мирового и национального АПК. Сформулированы основные задачи развития аграрного сектора экономики: рост производства продукции на душу населения; обеспечение физической и экономической доступности продовольствия в необходимом качестве и ассортименте. Выявлено, что объёмы производства основных продуктов питания в России в 2015 г. не достигли показателей 1990 г., а потребление основных продуктов питания в России по отдельным позициям существенно ниже рекомендуемой нормы. Установлена дефицитность рациона питания населения страны по овощам и бахчевым, фруктам, молоку и молокопродуктам. Доказана целесообразность реформирования аграрной сферы экономики России, включающая его ускоренную адаптацию к глобальным вызовам. К ним отнесены геополитическая напряжённость, ухудшение внешнеэкономической конъюнктуры и снижение внешнего спроса, взаимные экономические санкции, колебания индексов инфляции, сокращение потребительского спроса. Сделан вывод о том, что для роста эффективности функционирования АПК и укрепления национальной продовольственной безопасности, необходимы техникотехнологическая модернизация производства, совершенствование механизмов государственной поддержки, активное развитие инновационной среды

Ключевые слова: АГРОПРОМЫШЛЕННЫЙ КОМПЛЕКС, ПРОДОВОЛЬСТВЕННАЯ БЕЗОПАСНОСТЬ, ГЛОБАЛИЗАЦИЯ, АГРАРНОЕ ПРОИЗВОДСТВО, ПОТРЕБЛЕНИЕ ПРОДУКТОВ ПИТАНИЯ, ИННОВАЦИОННОЕ РАЗВИТИЕ
UDC: 338.242 .4

Economics

AGROINDUSTRIAL COMPLEX AND ITS ROLE
IN SUPPORT OF NATIONAL FOOD SECURITY

Melnikov Boris Aleksandrovich

postgraduate student of the Economic faculty melnikov_ba@gw.tander.ru

Kuban State Agrarian University,

Krasnodar, Russia

A comprehensive assessment of the state of the agroindustrial complex of Russia is given and its role in ensuring national food security is defined. The main directions of ensuring state food sovereignty in the conditions of global challenges are substantiated. The scheme of interaction between the world and national agroindustrial complex is presented. The main tasks of development of the agrarian sector of the economy are formulated: the growth of production per capita; ensuring physical and economic accessibility of food in the required quality and assortment. It was revealed that the volume of production of basic food products in Russia in 2015 did not reach the indicators of 1990, and the consumption of basic food products in Russia by individual items is significantly lower than the recommended rate. Deficiency of a diet of the population of the country on vegetables and melons, fruit, milk and dairy products is established. The expediency of reforming the agrarian sphere of the Russian economy is proved, including its accelerated adaptation to global challenges. They include geopolitical tensions, deterioration in the external economic environment and a reduction in external demand, mutual economic sanctions, fluctuations in inflation indices, and a reduction in consumer demand. It was concluded that for the increase in the efficiency of the functioning of the agroindustrial complex and the strengthening of national food security, technical and technological modernization of production, improvement of the mechanisms of state support, active development of the innovation environment are needed

Keywords: AGROINDUSTRIAL COMPLEX, FOOD SECURITY, GLOBALIZATION, AGRARIAN PRODUCTION, CONSUMPTION OF FOODSTUFFS, INNOVATIVE DEVELOPMENT

\title{
Doi: 10.21515/1990-4665-128-096
}


Агропромышленный комплекс является сложной социальноэкономической системой, включающей большое разнообразие структурных элементов, образующих его подсистемы. Особая роль в этой системе отводится сельскому хозяйству - центральному звену АПК, которое является фундаментом обеспечения как глобальной, так и национальной продовольственной безопасности.

В настоящее время эффективное развитие отечественного АПК является задачей стратегической важности, от решения которой зависит перспектива обеспечения продовольственной безопасности России. Это связано с тем, что в условиях геополитической турбулентности, разразившегося мирового финансово-экономического кризиса, связанного с падением мировых цен на нефть, эскалацией военного напряжения в Сирии и Украине, экономических санкций именно от уровня конкурентоспособности отечественного аграрного сектора экономики зависит благополучие граждан России, социальная и экономическая стабильность в стране [5].

Современное состояние АПК России характеризуется отсутствием эффективного механизма управления, позволяющего регулировать воспроизводственные процессы и адаптировать аграрный сектор экономики к трансформирующимся рыночным отношениям. Специфика функционирования отечественного АПК связана с его относительно низкой инвестиционной привлекательностью, обусловленной высокими производственнофинансовыми рисками и недостаточным уровнем финансовой обеспеченности отечественных товаропроизводителей. Недостаточно эффективный механизм оказания бюджетной поддержки российским аграриям, высокие процентные ставки по кредитам, большая доля устаревшей техники не дают большинству сельскохозяйственных организаций производить конкурентоспособную продукцию, лишают возможности осваивать и распространять инновации. В сложившихся условиях существенно возрастают требования к уровню профессионализма менеджмента организаций АПК, 
который выражается в способности оперативно реагировать на новые экономические реалии в условиях рыночной неопределенности [3].

В этой связи важно активизировать разработки по научнометодическому обеспечению мероприятий, связанных с совершенствованием организационно-экономического механизма обеспечения глобальной и национальной продовольственной безопасности в условиях политических, военных и финансово-экономических вызовов мировой экономики.

Особая значимость устойчивого развития национального АПК определяется необходимостью в короткие сроки обеспечить прорыв в производстве отечественного сельскохозяйственного сырья и продовольствия, преодолеть негативные тенденции и создать комплекс условий для эффективной реализации политики импортозамещения [2].

Следует подчеркнуть, что организационно-экономический механизм обеспечения как глобальной, так и национальной продовольственной безопасности является сложноорганизованной системой, состоящей из множества подсистем различного порядка и соподчинённости, от эффективного управления которой зависит состояние мирового и отечественного агропродовольственного рынков.

Национальная продовольственная безопасность занимает важное место в жизнеобеспечении населения страны, так как наличие доступного продовольствия является базовым условием жизнедеятельности человека. Продукты питания необходимы ежедневно каждому жителю планеты, а уровень и экологическая безопасность питания определяют здоровье нации и продолжительность жизни людей.

Обеспечение продовольственной безопасности следует рассматривать как многоуровневую систему с различными целями и задачами. Целью обеспечения как глобальной, так и национальной продовольственной безопасности является решение глобальной и национальной продовольственной проблемы. Схема взаимодействия мирового и национального 
АПК представлена на рисунке 1.

Основными задачами развития АПК в глобальном и национальном масштабах в условиях внешнеэкономических вызовов являются: рост производства продукции на душу населения; обеспечение физической и экономической доступности продовольствия в необходимом качестве и ассортименте; технико-технологическая модернизация производства; учёт национально-этнических обычаев и традиций; достижение критериев, определённых Доктриной продовольственной безопасности страны; мониторинг и постоянная корректировка состояния продовольственного обеспечения населения. При этом продовольствие должно соответствовать всем необходимым экологическим и санитарным нормам, удовлетворяющим потребности человека с учётом национальных особенностей и обеспечивающим максимальную продолжительность жизни [6]. 


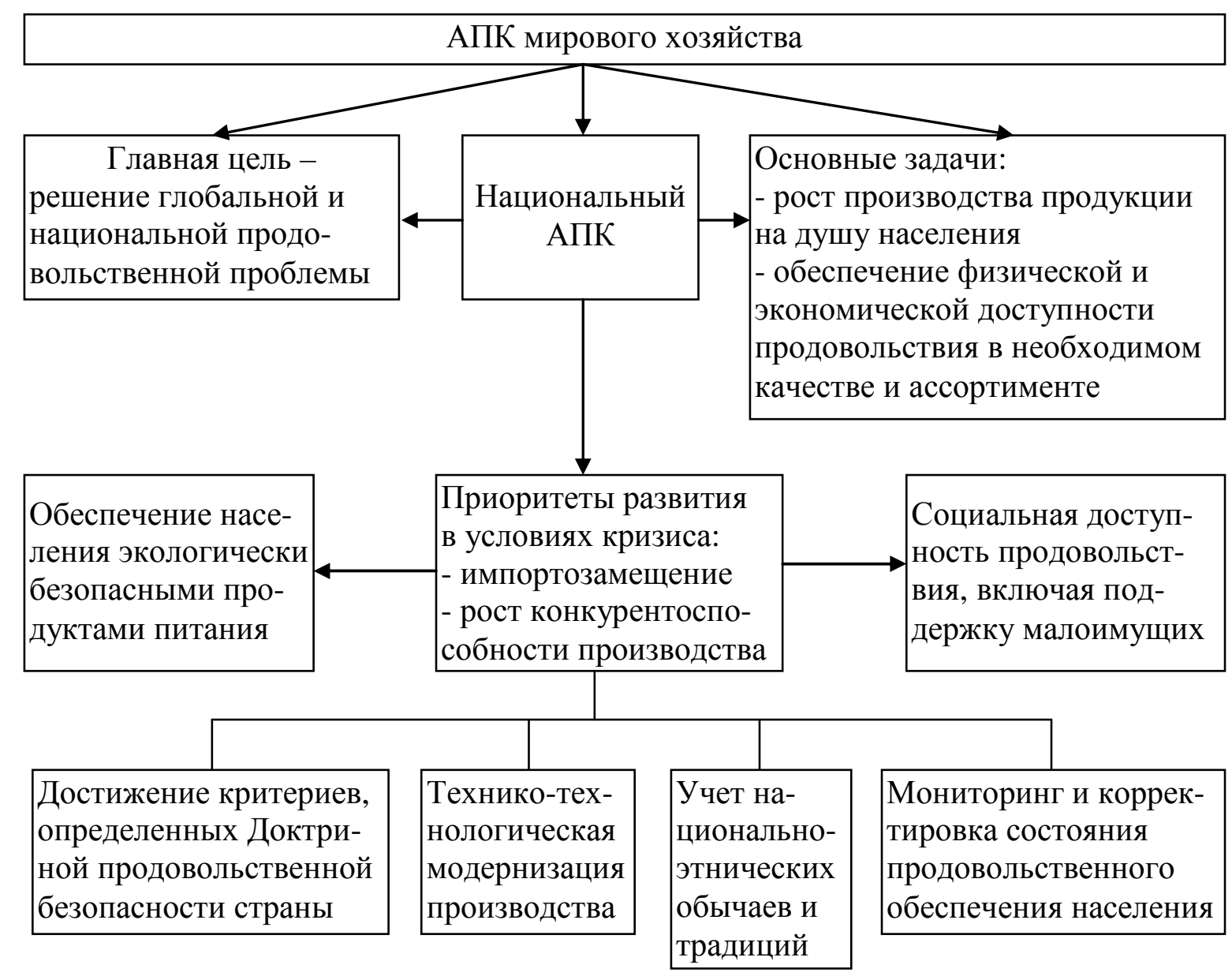

Рисунок 1 - Схема взаимодействия мирового и национального АПК

Кроме рекомендованных основных пороговых значений достижения продовольственной безопасности, определённых Доктриной продовольственной безопасности страны, необходимо оценивать и разрабатывать приоритеты развития АПК в аспекте обеспечения его конкурентоспособности и устойчивого экономического роста. Постоянному мониторингу должны подвергаться следующие составляющие АПК: ресурсный потенциал, (включающий земельные, кадровые, материально-технические, финансовые и предпринимательские ресурсы, производственные мощности), финансово-экономическое состояние отраслей и организаций АПК; уровень развития и устойчивости сельскохозяйственного производства; угрозы и риски продовольственной безопасности, масштабы импорта, в том 
числе в сравнении с собственным производством и потребностью в продовольствии.

В настоящее время актуализируются проблемы снижения импортной зависимости страны от завозимого продовольствия, ужесточаются требования к соответствию продовольственной безопасности отечественному и международному законодательству, включая ВТО.

Основные перспективы устойчивого развития отечественного АПК тесно связаны с минимизацией угроз производственно-финансовых рисков, прогнозированием и предотвращением их отрицательных последствий путем формирования эффективной системы управления.

Результатами развития национального АПК в ближайшей перспективе, способными переломить негативные тенденции развития отечественного агропродовольственного рынка, должны стать: устойчивый экономический рост основных подотраслей, оптимизация отраслевой структуры, технологическая модернизация производства, активное развитие инновационной среды. Перечисленные направления взаимосвязаны и взаимообусловлены, что подчёркивает комплексный характер проблем АПК, требующих решения. 
Значительное влияние на функционирование АПК России оказали реализация приоритетного национального проекта «Развитие АПК», Доктрина продовольственной безопасности Российской Федерации (утверждена Указом Президента Российской Федерации от 30 января 2010 г. №120), и реализация Государственной программы развития сельского хозяйства и регулирования рынков сельскохозяйственной продукции, сырья и продовольствия на 2013-2020 годы. Мероприятия, реализованные в рамках данных государственных программ, позволили частично стабилизировать отечественный агропродовольственный рынок, однако проблема удовлетворения платежеспособного спроса населения на отечественную продукцию осталась не решенной [8].

Расчёты показывают, что объёмы производства основных продуктов в России в 2015 г. не достигли показателей 1990 г. (кроме семян подсолнечника и сахарной свёклы). Так, производство зерна в 2015 г. составило только 87,7\% к уровню 1990 г., скот и птица на убой (в живой массе) $86,5 \%$, молоко - 55,3\%, яйца - 89,5\%. По отношению к 2000 г. показатели по всем видам продукции были превышены, за исключением молока (снижение составило 4,6\%).

Таблица 1 - Производство основных продуктов растениеводства и животноводства в России (в хозяйствах всех категорий) [9]

\begin{tabular}{|l|c|c|c|c|c|c|c|}
\hline \multicolumn{1}{|c|}{ Вид продукции } & 1990 г. & 2000 г. & 2010 г. & 2014 г. & 2015 г. & \multicolumn{2}{|c|}{2015 г. в \% к } \\
\cline { 7 - 9 } & & & & & 1990 г. & 2000 г. \\
\hline $\begin{array}{l}\text { Зерно (в весе после } \\
\text { доработки), млн т }\end{array}$ & 116,7 & 65,5 & 61,0 & 103,1 & 102,4 & 87,7 & 156,3 \\
\hline Подсолнечник, млн т & 3,4 & 3,9 & 5,3 & 8,5 & 9,3 & 273,5 & 238,4 \\
\hline Сахарная свёкла, млн т & 32,3 & 14,1 & 22,3 & 33,5 & 39,0 & 120,7 & 276,5 \\
\hline $\begin{array}{l}\text { Скот и птица на убой } \\
\text { (в живой массе), млн т }\end{array}$ & 15,6 & 7,0 & 7,6 & 12,9 & 13,5 & 86,5 & 192,8 \\
\hline Молоко, млн т & 55,7 & 32,3 & 31,2 & 30,8 & 30,8 & 55,3 & 95,4 \\
\hline Яйца, млрд шт & 47,5 & 34,0 & 36,9 & 41,2 & 42,5 & 89,5 & 125,0 \\
\hline
\end{tabular}

Согласно уточненной оценке, валовой сбор зерновых и зернобобовых культур в России в 2016 г. составил 120,67 млн тонн. При этом следует 
подчеркнуть, что в технически удовлетворительном состоянии находятся только $40 \%$ элеваторов. В еще худшем состоянии находятся амбары. Но фермеры соглашаются хранить зерно в них из-за дороговизны услуг элеваторов. Построить собственные элеваторы крестьянские хозяйства не решаются из-за длительных сроков окупаемости - до 15-20 лет [2].

В соответствии с приказом Министерства здравоохранения РФ от 19 августа 2016 г. №614 «Об утверждении Рекомендаций по рациональным нормам потребления пищевых продуктов, отвечающих современным требованиям здорового питания» установлены нормы потребления продуктов, которые рекомендованы человеку для рационального питания, чтобы удовлетворить потребности во всех пищевых нутриентах и вести активный, здоровый образ жизни [1].

Расчёты показали, что в 2015 г. потребление основных продуктов питания в России по отношению к 2000 г. увеличилось, но по отдельным продуктам существенно ниже рекомендуемой нормы (табл. 2). Так, дефицит овощей и бахчевых в рационе населения страны составляет 20,7\%, фруктов - 39,0\%, молока и молокопродуктов - 26,5\%.

Таблица 2 - Потребление основных продуктов питания в России (на душу населения в год, кг)

\begin{tabular}{|l|c|c|c|c|c|c|c|c|}
\hline \multirow{2}{*}{$\begin{array}{l}\text { Наименование } \\
\text { продуктов }\end{array}$} & $\begin{array}{c}\text { Рекомен- } \\
\text { дуемая } \\
\text { рацио- } \\
\text { нальная } \\
\text { норма }\end{array}$ & 1990 г. & 2000 г. & 2010 г. & 2014 г. & 2015 г. & 2000 г. & $\begin{array}{c}\text { рекомен- } \\
\text { дуемой } \\
\text { норме }\end{array}$ \\
\hline $\begin{array}{l}\text { Хлебные } \\
\text { продукты }\end{array}$ & 96 & 120 & 117 & 120 & 118 & 118 & 100,9 & 122,9 \\
\hline Картофель & 90 & 106 & 109 & 104 & 111 & 112 & 124,4 & 124,4 \\
\hline $\begin{array}{l}\text { Овощи и } \\
\text { бахчевые }\end{array}$ & 140 & 89 & 79 & 101 & 111 & 111 & 140,5 & 79,3 \\
\hline Фрукты & 100 & 35 & 32 & 58 & 64 & 61 & 190,6 & 61,0 \\
\hline Сахар & 24 & 47 & 35 & 39 & 40 & 39 & 111,4 & 162,5 \\
\hline Мясопродукты & 73 & 75 & 45 & 69 & 74 & 73 & 162,2 & 100,0 \\
\hline $\begin{array}{l}\text { Молоко и моло- } \\
\text { копродукты }\end{array}$ & 325 & 387 & 215 & 247 & 244 & 239 & 111,2 & 73,5 \\
\hline Яйца & 260 & 297 & 229 & 269 & 269 & 269 & 117,5 & 103,5 \\
\hline
\end{tabular}


Существует множество направлений развития аграрного сектора экономики страны, которые формируются под воздействием различных внешних и внутренних факторов, но основными являются инерционное и инновационное.

Процесс, в результате которого замедляются темпы экономического роста, снижается его качество, происходит стагнация развития и усиливаются инфляционные процессы, называют инерционным. Состояние инерционности социально-экономической системы, как правило, сопровождается кризисными явлениями, ростом безработицы, структурными диспропорциями в развитии экономики, негативными тенденциями системы обеспечения продовольственной безопасности.

Качественный экономический рост исследователи связывают с инновационным развитием, предполагающим рост эффективности функционирования системы, улучшение качества жизни населения, расширенное воспроизводство, удовлетворение растущих потребностей населения в качественных продуктах и услугах.

Существующие направления развития социально-экономических систем могут быть реализованы в модифицированных видах, содержащих признаки и свойства каждого из направлений. Например, варианты развития могут быть прорывными, умеренными, догоняющими, стабилизационными и пр.

По мнению автора, современное развитие агропромышленного комплекса России можно охарактеризовать как «догоняющее», имея ввиду отсутствие самостоятельной поступательной динамики, когда механизмы, регулирующие функционирование данной системы работают не на опережение потенциальных конкурентов, а подстраиваются под постоянно изменяющиеся условия на внешних и внутренних агропродовольственных рынках.

Исследования подтверждают, что система экономических отношеhttp://ej.kubagro.ru/2017/04/pdf/96.pdf 
ний в аграрной сфере экономики России нуждается в реформировании, включающем ускоренную адаптацию аграрного сектора к вызовам мировой экономики. К ним можно отнести геополитическую напряжённость, ухудшение внешнеэкономической конъюнктуры и снижение внешнего спроса, взаимные экономические санкции, колебания индексов инфляции, сокращение потребительского спроса. Сложившаяся ситуация требует пересмотра ключевых приоритетов развития аграрной сферы и в этой связи государственная программа развития сельского хозяйства на 2013-2020 гг. постоянно корректируется [7].

Так, в государственной программе учтено увеличение сроков субсидирования инвестиционных кредитов с 8 до 15 лет с компенсацией за счет федерального бюджета затрат на уплату процентов в размере $100 \%$ ключевой ставки Банка России. Также дополнения и исправления внесены для приведения показателей в соответствие с принятыми законами о федеральном бюджете и реальным ресурсным обеспечением [4].

В настоящее время Минсельхоз России продолжает работу по совершенствованию государственной программы. В рамках этой работы будет проведен анализ эффективности мер поддержки и расходования средств федерального бюджета, в результате будут предложены соответствующие изменения.

Интеграция в мировые хозяйственные связи и современные политические и экономические вызовы российской экономики предполагают создание конкурентоспособного аграрного производства, прежде всего, за счёт приведения в соответствие его технико-технологических параметров мировым стандартам.

Значение эффективного развития АПК для экономики страны определяется его ролью в обеспечении продовольственной безопасности, которая является проблемой как глобального, так и национального масштаба, требующей решения на всех уровнях существования человеческой цивили- 
зации - в мире, в стране, регионе, семье и касающейся каждого человека планеты.

Составной частью стратегии развития АПК должна стать её инновационная составляющая, которая реализуется через развитие инновационной среды, предполагающей активное освоение и внедрение новшеств во всех сферах АПК. Это позволит формировать конкурентоспособное производство продукции и обеспечивать её высокое качество.

Таким образом, для достижения целей обеспечения глобальной и национальной продовольственной безопасности и реализации направлений развития аграрной сферы на инновационной основе необходима корректировка стратегии развития национальных АПК в условиях вызовов глобального рынка и смене внешнеэкономических ориентиров.

Современная экономическая ситуация обуславливает необходимость в кратчайшие сроки обеспечить рост объёмов сельскохозяйственного производства, достичь пороговых значений обеспечения национальной продовольственной безопасности и конкурентоспособных параметров производимой аграрной продукции.

\section{Литература}

1. Приказ Министерства здравоохранения РФ от 19 августа 2016 г. №614. Об утверждении Рекомендаций по рациональным нормам потребления пищевых продуктов, отвечающих современным требованиям здорового питания [Электронный ресурс]. - Режим доступа - ГАРАНТ.РУ: http://www.garant.ru/products/ipo/prime/doc/71385784/\#ixzz4cf934bT4.

2. Артемова Е.И. Обеспечение конкурентоспособности регионального агропромышленного комплекса в условиях импортозамещения / Е.И. Артемова, Е.В. Плотникова // Политематический сетевой электронный научный журнал Кубанского государственного аграрного университета. - 2016. - №119. - С. 524-538.

3. Артемова Е.И. Совершенствование механизмов государственного регулирования агропромышленного комплекса Краснодарского края в современных условиях / Е.И. Артемова, Е.В. Плотникова // Политематический сетевой электронный научный журнал Кубанского государственного аграрного университета. - 2016. - №117. - С. 1072-1084.

4. В Госпрограмму развития сельского хозяйства добавлена поддержка кооперативов / Источник: Минсельхоз РФ, 21.04.2014 - http://selcoop.ru/news/2014/04/21/vgosprogrammu-razvitiya-selskogo-khozya/(Дата обращения 15.01.2017) 
5. Кудряков В.Г. Государственное регулирование региональной продовольственной безопасности в условиях санкционного режима / В.Г. Кудряков, Е.И. Артемова, Е.В. Плотникова // Политематический сетевой электронный научный журнал Кубанского государственного аграрного университета. - 2016. - №123. - С. 2042-2057.

6. Набоков П.Н. Государственное регулирование реализации доктрины национальной продовольственной безопасности России // Набоков П.Н., Лазько Л.В. // Экономика и управление: актуальные вопросы теории и практики. Материалы IV международной научно-практической конференции. - 2016. - С. 253-258.

7. Платонова Е. Родине не хватает закромов [Электронный ресурс]. - Режим доступа - https://www.gazeta.ru/business/2016/08/11/10118735.shtml (Дата обращения 28.03.2017)

8. Плотникова Е.В. Программно-целевое регулирование агропромышленного комплекса Краснодарского края / Е.В. Плотникова // Научное обеспечение агропромышленного комплекса. Отв. за вып. А.Г. Кощаев. - 2016. - С. 545-546.

9. Россия в цифрах. 2016: Статистический сборник. - М.: Росстат, 2016 - 543 с.

\section{References}

1. Prikaz Ministerstva zdravoohranenija RF ot 19 avgusta 2016 g. №614. Ob utverzhdenii Rekomendacij po racional'nym normam potreblenija pishhevyh produktov, otvechajushhih sovremennym trebovanijam zdorovogo pitanija [Jelektronnyj resurs]. - Rezhim dostupa $-$

GARANT.RU: http://www.garant.ru/products/ipo/prime/doc/71385784/\#ixzz4cf934bT4.

2. Artemova E.I. Obespechenie konkurentosposobnosti regional'nogo agropromyshlennogo kompleksa v uslovijah importozameshhenija / E.I. Artemova, E.V. Plotni-kova // Politematicheskij setevoj jelektronnyj nauchnyj zhurnal Kubanskogo gosudar-stvennogo agrarnogo universiteta. - 2016. - №119. - S. 524-538.

3. Artemova E.I. Sovershenstvovanie mehanizmov gosudarstvennogo reguliro-vanija agropromyshlennogo kompleksa Krasnodarskogo kraja v sovremennyh uslovijah / E.I. Artemova, E.V. Plotnikova // Politematicheskij setevoj jelektronnyj nauchnyj zhurnal Kubanskogo gosudarstvennogo agrarnogo universiteta. - 2016. - №117. - S. 1072-1084.

4. V Gosprogrammu razvitija sel'skogo hozjajstva dobavlena podderzhka kooperativov / Istochnik: Minsel'hoz RF, 21.04.2014 - http://selcoop.ru/news/2014/04/21/vgosprogrammu-razvitiya-selskogo-khozya/(Data obrashhenija 15.01.2017)

5. Kudrjakov V.G. Gosudarstvennoe regulirovanie regional'noj prodovol'st-vennoj bezopasnosti v uslovijah sankcionnogo rezhima / V.G. Kudrjakov, E.I. Artemova, E.V. Plotnikova // Politematicheskij setevoj jelektronnyj nauchnyj zhurnal Kubanskogo gosudarstvennogo agrarnogo universiteta. - 2016. - №123. - S. 2042-2057.

6. Nabokov P.N. Gosudarstvennoe regulirovanie realizacii doktriny nacio-nal'noj prodovol'stvennoj bezopasnosti Rossii // Nabokov P.N., Laz'ko L.V. // Jeko-nomika i upravlenie: aktual'nye voprosy teorii i praktiki. Materialy IV mezhdunarodnoj nauchnoprakticheskoj konferencii. - 2016. - S. 253-258.

7. Platonova E. Rodine ne hvataet zakromov [Jelektronnyj resurs]. - Rezhim dostupa https://www.gazeta.ru/business/2016/08/11/10118735.shtml (Data obrashhenija 28.03.2017)

8. Plotnikova E.V. Programmno-celevoe regulirovanie agropromyshlennogo kompleksa Krasnodarskogo kraja / E.V. Plotnikova // Nauchnoe obespechenie agropromyshlennogo kompleksa. Otv. za vyp. A.G. Koshhaev. - 2016. - S. 545-546.

9. Rossija v cifrah. 2016: Statisticheskij sbornik. - M.: Rosstat, 2016 - 543 s. 